\title{
Doppler Ultrasound of Hepatic Vessels in the Diagnosis of Cirrhosis of the Liver in Togo
}

\author{
Lantam Sonhaye1, Abarchi Habibou Boube1, Abdoulatif Amadou1, Bérésa Kolou1, \\ Mohaman Djibril'2, Bidamin Ntimon'3 ${ }^{3}$ Mazamaesso Tchaou', Nouhou Mamoudou Garba1, \\ Lama Kègdigoma Agoda-Koussema1, Komlavi Adjenou ${ }^{1}$
}

${ }^{1}$ Department of Radiology, University Teaching Hospital of Lomé, Lomé, Togo

${ }^{2}$ Department of Internal Medicine, University Teaching Hospital of Lomé, Lomé, Togo

${ }^{3}$ Department of Radiology, University Teaching Hospital of Kara, Kara, Togo

Email: habibouabarchi@gmai.com

How to cite this paper: Sonhaye, L., Boube, A.H., Amadou, A., Kolou, B., Djibril, M., Ntimon, B., Tchaou, M., Garba, N.M., Agoda-Koussema, L.K. and Adjenou, K. (2018) Doppler Ultrasound of Hepatic Vessels in the Diagnosis of Cirrhosis of the Liver in Togo. Open Journal of Radiology, 8, 53-63.

https://doi.org/10.4236/ojrad.2018.81007

Received: February 3, 2018

Accepted: March 19, 2018

Published: March 22, 2018

Copyright ( $\odot 2018$ by authors and Scientific Research Publishing Inc. This work is licensed under the Creative Commons Attribution International License (CC BY 4.0).

http://creativecommons.org/licenses/by/4.0/

(c) (7) Open Access

\begin{abstract}
The aim of this work is to evaluate the role of Ultrasound-Doppler in the hemodynamic study of hepatic vessels during the liver cirrhosis in Togo. Method: This was an analytic cross-sectional study that measured the velocimetric parameters of hepatic vessels in cirrhotic patients and in non-cirrhotic patients. Results: The velocimetric parameters of the hepatic artery, the portal vein, and the hepatic veins were measured in 50 cirrhotic patients and 50 non-cirrhotic The caliber of the portal vein was significantly increased in cirrhotic patients compared to non-cirrhotic patients with $13.11 \pm 2.16 \mathrm{~mm}$ versus $11.45 \pm 1.02(\mathrm{p}<0.00006)$. The systolic velocity and the hepatic artery resistance index were significantly raised in the cirrhotic patients compared to the non-cirrhotic with $67.32 \pm 22.77$ versus $49.97 \pm 17.24$ (p-value $<0.00004$ ) respectively, and $0.78 \pm 0.07$ against $0.72 \pm 0.08$ ( $\mathrm{p}<0.00006)$. The caliber of the hepatic veins was significantly decreased in the cirrhotic patients compared to the non-cirrhotic patients $(\mathrm{p}<0.0003)$. There was no correlation between the gender of the patients and the change in the hemodynamics of the hepatic vessels. Conclusion: The hemodynamic study of the hepatic vessels can and must rightly be a diagnostic argument for liver cirrhosis.
\end{abstract}

\section{Keywords}

Doppler, Hepatic Vessels, Diagnosis, Cirrhosis, Togo

\section{Introduction}

Cirrhosis is defined as a diffuse disorganization of the liver architecture, with 
annular fibrosis delineating hepatocyte nodules in clusters that are called regeneration nodules [1].

The standard diagnosis of cirrhosis is still histology [2]. However, this technique suffers from a fake negative rate of up to $24 \%$ [2]. Also, because of the lack of technical means and the limitations in the histology method within our regions, this diagnosis is based on a bundle of clinical, biological, and radiological arguments [3]. The main radiological method is the Doppler ultrasound.

Several studies have been conducted around the world to determine the contribution of ultrasound coupled or not to Doppler in the diagnosis of cirrhosis [4] [5] [6]. However, in Togo, no study has been conducted on the use of Doppler in the diagnosis of hepatic cirrhosis, despite the frequency of the pathology [3].

We conducted this study to evaluate the Ultrasound-Doppler's hemodynamic variations of the hepatic vessels during the liver cirrhosis in Togo.

\section{Method}

This was an analytic cross-sectional study that measured the velocimetric parameters of hepatic vessels of the patients treated in the Hepato-gastroenterology department of the Lomé University Hospital Center for the liver's cirrhosis and of volunteers, non-cirrhotic, not having any known liver pathology and having a normal liver function.

We excluded the patients who had a high blood pressure or who got a liver mass, hepatocellular carcinoma, a heart failure, a kidney failure or an abundant ascites.

We utilized the ESAOTE My lab mark of ultrasound provided with multi-frequency probes, a color Doppler module, a pulsed Doppler with its different modes: duplex, triplex, and alternate, with the patients on least six hours of fasting.

All examinations were performed by the same operator, a radiologist with at least five years of experience in the visceral Doppler exam.

The examination began with a study of the hepatic morphology per subcostal, intercostal transverse and sagittal sections.

The filter was set between 50 and $100 \mathrm{~Hz}$. The pulse repetition frequency (PRF) was manually set to operate according to the quality of the resulting plot and the observed velocities. The firing angle was between 30 and 60. The Doppler gate was as possible as possible in the center of the vessel to be surveyed.

All the recordings were made in the subject being in apnea in the middle of breathing. The exploration was done for each of the hepatic vessels.

We identified the portal vein, including the segment between the spleno-portal junction and the intrahepatic bifurcation that was shaped as an anechoic tube within which we measured the largest diameter, as a caliber.

The color Doppler enabled us to detect the blood flow.

The design obtained using pulsed Doppler was secondarily analyzed to deter- 
mine the speeds and the different indexes.

We identified the hepatic artery by using a costal or intercostal approach. This artery visualization was difficult for some patients, but in most cases, the hepatic artery was anterior and slightly medial to the portal vein.

The pulsed Doppler mode was used to obtain the plot of at least three consecutive pulses that we examined and on which we measured the velocimetry parameters (velocities and indices).

We identified the hepatic veins by using intercostal and recurrent subcostal cuts. We preferably chose the right hepatic vein. The Doppler window was placed in the center of the vein, two centimeters from its meeting with the inferior vena cava.

The size of the portal vein, the direction of its flow, its spectrum, its average velocity ( Vm), its maximum systolic velocity (Vsmax), and its diastolic velocity (Vdias) were studied. The vein pulse index of the portal vein (VPI) corresponds to the ratio of the difference between the maximum systolic speed and the diastolic rate on the systolic maximum speed.

The maximum systolic velocity, the average velocity, the diastolic velocity, the resistance index (RI), and the pulse index (PI) were the variables analyzed on the hepatic artery.

The studied parameters of the hepatic veins were the caliber, the spectrum, and the flow.

The hepatic vascular index (HVI) is the ratio of the average velocity of the portal vein to the pulse index (PI).

The arterio-portal ratio (APR) is the ratio of the systolic velocity of the hepatic artery to the maximum systolic velocity of the portal vein.

The Chi-2 statistical test was applied after crossing to determine the interdependence of the qualitative variables with values greater than 2.5. For the variables with values less than 2.5 , the Fisher test was used. For the numerical averages, the Student's test was used. The relationship between the continuous values was analyzed using the Pearson correlation test. These tests were significant when the $p$-value (random part) was less than 0.05 .

\section{Results}

The caliber of the portal vein was abnormal in $52 \%$ of cirrhotic patients and in $6 \%$ of the case of non-cirrhotic patients. The difference was statistically significant $\left(p\right.$-value $\left.=4.75 \times 10^{-7}\right)$.

The averages of the velocimetry variables of cirrhotic and non-cirrhotic patients are shown in Table 1.

The Vsmax, Vm, RI, hepatic artery PI, as well as the portal vein caliber, had a statistically significant increase in values in the cirrhotic patients versus noncirrhotic patients (Figure 1 \& Figure 2).

The sensitivity and the specificity of the resistance index for a value of 0.77 were respectively $54 \%$ and $68 \%$. 
Hepatic veins were normal in all the non-cirrhotic patients compared to $36 \%$ in the cirrhotic patients. $\left(P\right.$-value $\left.=3.01 \times 10^{-11}\right)$. The Sensitivity and specificity were $64 \%$ and $100 \%$, respectively.

A demodulation of the hepatic vein spectrum was found in $52 \%$ of the cirrhotic patients (Figure 3) whereas there was no change in the spectrum in the non-cirrhotic patients $\left(\mathrm{p}\right.$-value $=1.202 \times 10^{-8}$ )

The blood flow in the hepatic veins was hepatofugal in both cirrhotic and non-cirrhotic patients.

The relationship between age and the speed parameters assessed by the Pearson correlation test noted a linear and positive correlation between age and RI $(\mathrm{p}$-value $=0.02)$ and age and PI $(\mathrm{p}$-value $=0.021)$.

There was no correlation between sex and the statistically significant variations observed between the speed parameters in cirrhotic and non-cirrhotic patients.

\section{Discussion}

\subsection{Portal Vein}

We found a statistically significant $(\mathrm{p}$-value $=0.00006)$ increase in the portal vein average caliber in cirrhotic versus non-cirrhotic patients.

The increase of the caliber is secondary to the increase of the pressure in the

Table 1. Comparison of the Doppler averages for Cirrhotic patients and Non-Cirrhotic Patients.

\begin{tabular}{|c|c|c|c|}
\hline & Cirrhotic patients & Non cirrhotic patients & $P$ value \\
\hline \multicolumn{4}{|l|}{ Portal vein } \\
\hline Caliber (mm) & $13.11 \pm 2.16$ & $11.45 \pm 1.02$ & 0.000066 \\
\hline Average speed $(\mathrm{cm} / \mathrm{s})$ & $15.50 \pm 5.46$ & $15.85 \pm 4.18$ & 0.71 \\
\hline Maximum systolic speed $(\mathrm{cm} / \mathrm{s})$ & $19.30 \pm 6.68$ & $19.58 \pm 5.03$ & 0.81 \\
\hline Diastolic speed $(\mathrm{cm} / \mathrm{s})$ & $13.11 \pm 6.64$ & $13.88 \pm 8.34$ & 0.4 \\
\hline VPI & $0.30 \pm 0.12$ & $0.27 \pm 0.11$ & 0.2 \\
\hline \multicolumn{4}{|l|}{ Hepatic artery } \\
\hline Average speed $(\mathrm{cm} / \mathrm{s})$ & $30.20 \pm 10.94$ & $25.75 \pm 13.16$ & 0.06 \\
\hline Maximum systolic speed $(\mathrm{cm} / \mathrm{s})$ & $67.32 \pm 22.77$ & $49.97 \pm 17.24$ & $4.09 \times 10^{-5}$ \\
\hline Diastolic speed $(\mathrm{cm} / \mathrm{s})$ & $13.99 \pm 6.64$ & $14.28 \pm 8.34$ & 0.84 \\
\hline RI & $0.78 \pm 0.07$ & $0.72 \pm 0.08$ & $6.54 \times 10^{-5}$ \\
\hline PI & $1.82 \pm 0.51$ & $1.49 \pm 0.40$ & 0.00056 \\
\hline HVI & $09.09 \pm 4.05$ & $11.52 \pm 4.55$ & 0.005 \\
\hline APR & $3.80 \pm 1.55$ & $2.71 \pm 1.16$ & 0.00015 \\
\hline
\end{tabular}

VPI: venous pulse index, RI: resistance index, PI: pulse index, HVI: hepatic vascular index, APR: arterioportal ratio. 

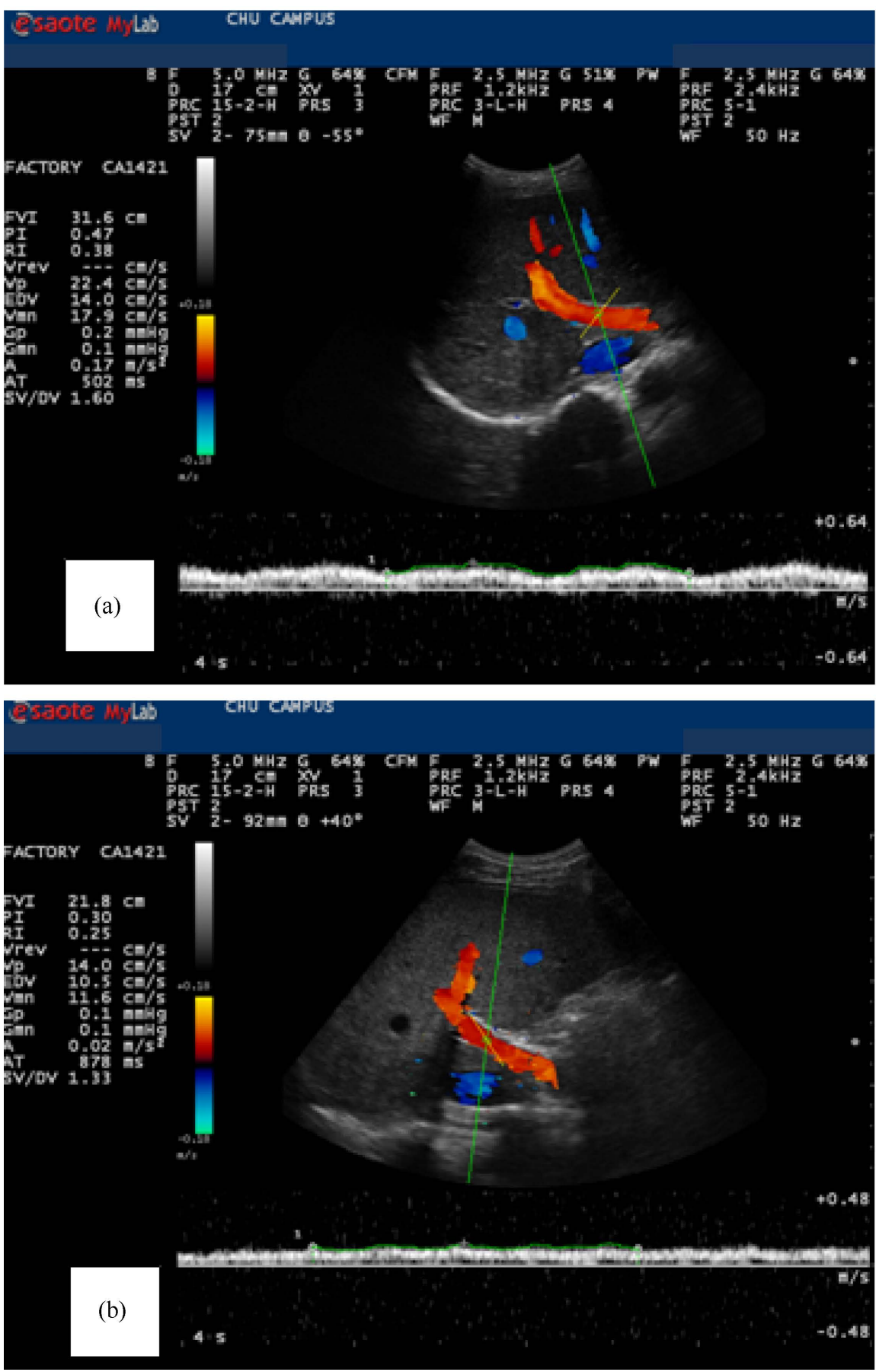

Figure 1. Flow and spectrum of portal vein. (a) In a non cirrhotic patient, hepatopetal flow and normal mean velocity $(17,9 \mathrm{~cm} / \mathrm{s})$; (b) in a cirrhotic patient, hepatopetal flow and decreased mean velocity $(11.6 \mathrm{~cm} / \mathrm{s})$.

portal system. Thus, an increased caliber of the portal vein should be given special attention in the search for other signs of cirrhosis. However, the diameter of the portal vein decrease and become normal again in case of portosystemic diversion. And when these diversion paths are important, the flow reverses and the caliber generally becomes normal or inferior to normal [7]. 

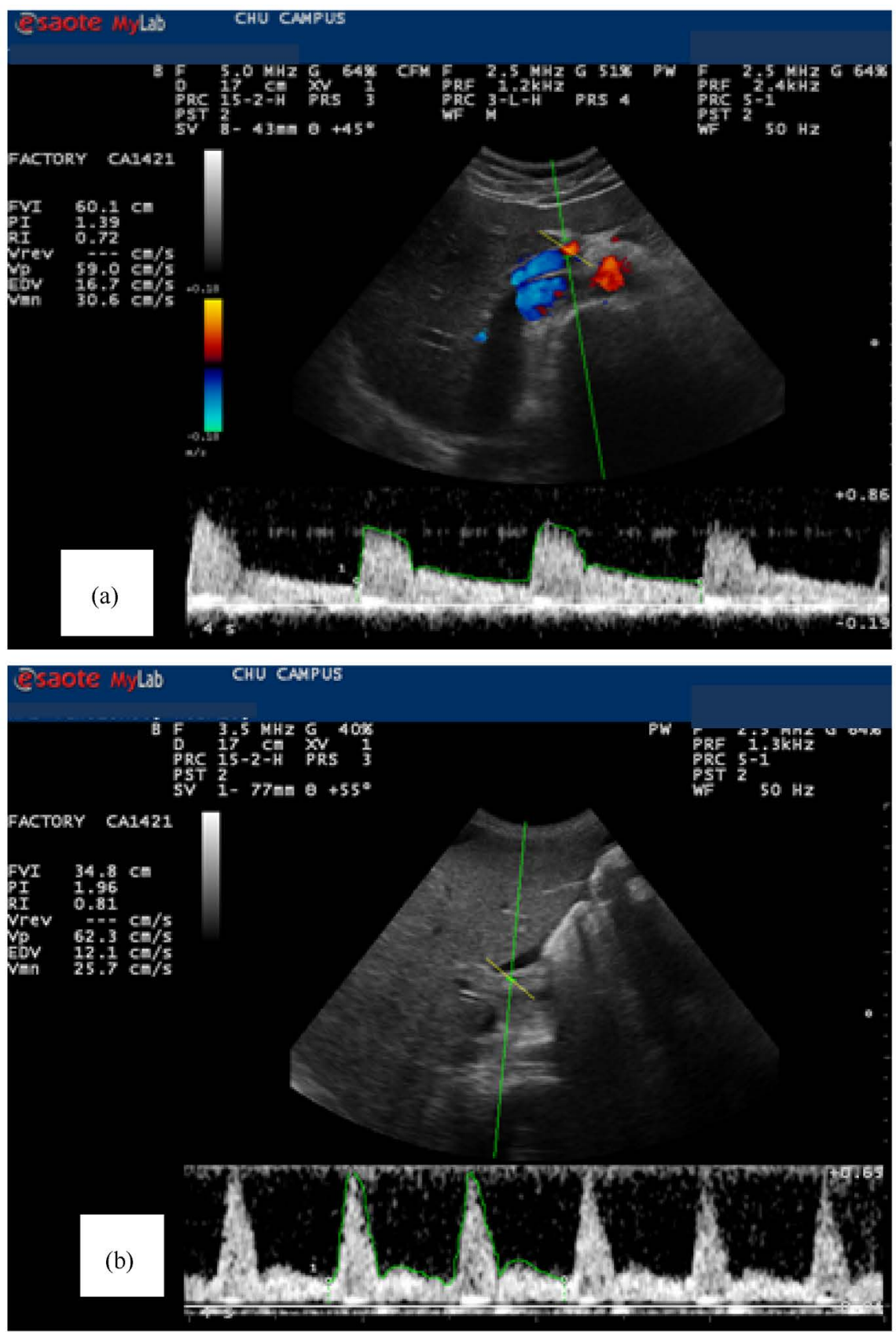

Figure 2. Hepatic artery spectrum. (a) in a non cirrhotic patient, the RI is 0.72 ; (b) in a cirrhotic patient, the RI is 0.81 .

We noticed in this study that a non-statistically significant decrease in the portal average velocity ( $\mathrm{p}$-value $=0.71$ ) of systolic and diastolic velocity in cirrhotic versus non-cirrhotic patients. The decrease in these speeds is explained by the loss of the flexibility of the hepatic parenchyma which becomes more difficult to irrigate and behaves as an obstacle to the normal flow of the blood. As a result, the blood flow slows down. This decrease in the velocity of the portal vein has been found by several authors. Iwao et al. [8] and Zironi al [7] respectively found an average of $11.0 \pm 2.4 \mathrm{~cm} / \mathrm{s}$ speed in cirrhotic patients versus $15.9 \pm 2.8$ 

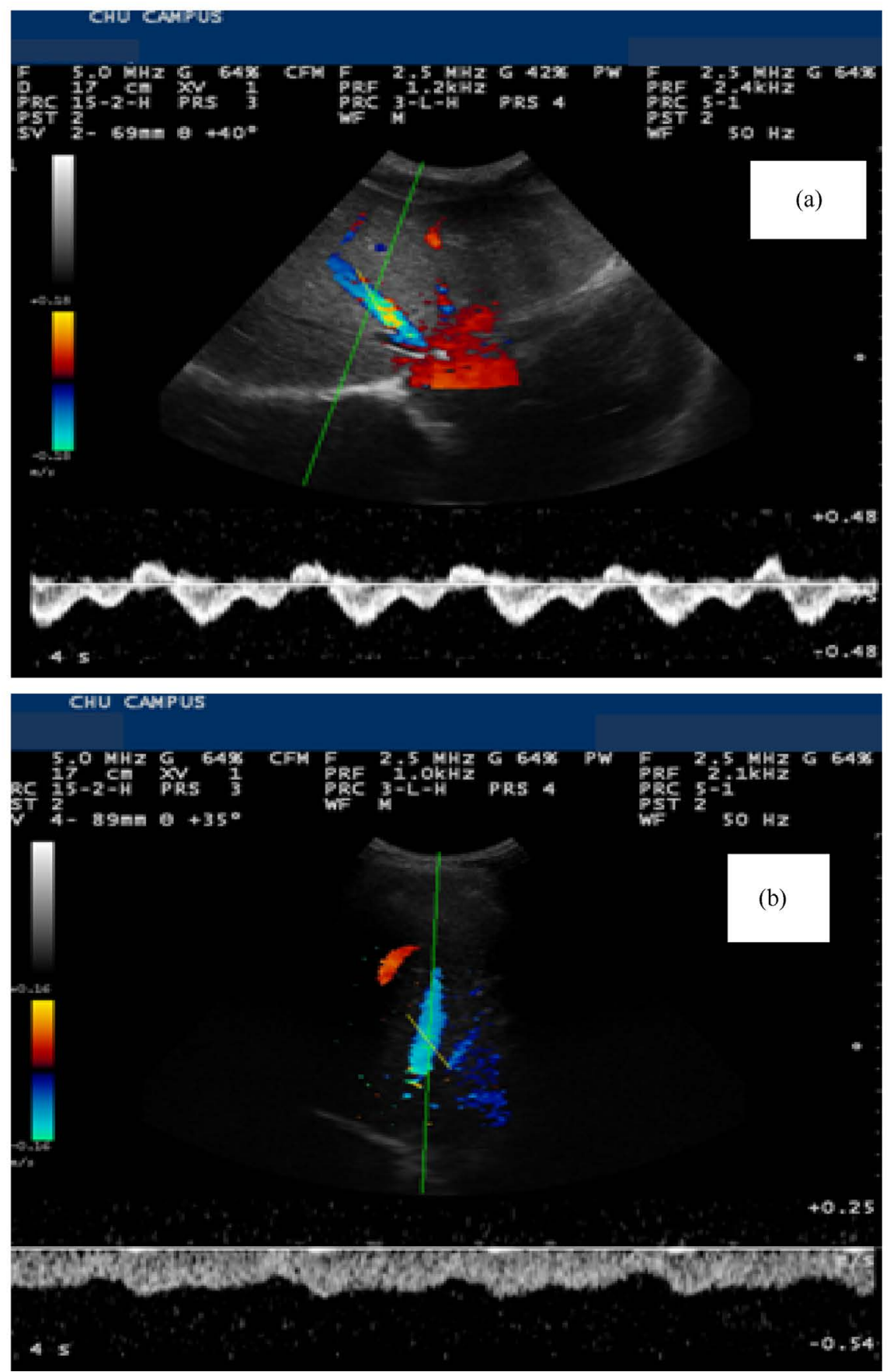

Figure 3. Hepatic vein spectrum. (a) normal waveform in a non cirrhotic patient characterized by a triphasic flow; (b) abnormal hepatic flow pattern in a cirrhotic patient characterized by a flat flow pattern.

$\mathrm{cm} / \mathrm{s}$ in controls and $(13.0 \pm 3.2 \mathrm{~cm} / \mathrm{s}$ against $19.6 \pm 2.6 \mathrm{~cm} / \mathrm{s}, \mathrm{p}<0.001)$ with however a statistically significant difference.

For a portal vein average velocity of $15 \mathrm{~cm} / \mathrm{s}$, Zironi [7] also found a sensitivity and a specificity of $88 \%$ and $96 \%$ respectively, not for the diagnosis of cirrhosis but for the detection of portal high blood pressure. This is still important because portal high blood pressure is a major complication of the cirrhosis of the 
liver.

Then, the lowering of the average speed can be an indirect sign of the diagnosis of hepatic cirrhosis.

Most studies [7] [8] found a decrease in portal vein velocimetry values in cirrhotic patients compared with non-cirrhotic subjects, but with different values.

This variation in values may be related to the difference in the material used, the test conditions and the measurement methods as reported in the literature [7] [9] [10] [11]. It can also be related to the variations in the position of the cursor and the Doppler window [12].

\subsection{Hepatic Artery}

The maximum systolic rate, as well as the average speed, had a statistically significant increase in cirrhotic patients compared to non-cirrhotic subjects.

The diastolic rate, meanwhile, experienced a non-statistically significant decrease in cirrhotic patients compared to controls.

The increase in the systolic velocity and the decrease in the diastolic velocity might be explained by the increase in the flow of the hepatic artery, which might attempt to curb the decrease the flow of the portal vein. This increased flow leads to the increase of the resistance in the arterial lair and, consequently, lead to the rise of the resistance and the pulse indices [13].

We also found in our study a statistically significant increase of the resistance index (IR) and the pulse index (PI).

This rise of the indices was found by Iwao [8] (PI $1.28 \pm 0.18$ against $0.95 \pm$ 0.17) Sacerdoti [14] (PI $1.3 \pm 0.29$ against $0.89 \pm 0.09$ and RI $0.71 \pm 0.07$ vs. 0.59 $\pm 0.04)$.

Taking into account the normal averages of the RI ( 0.55 - 0.81$)$ proposed by the literature [15] [16] [17], we found in our study $46 \%$ pathological IR and $86 \%$ pathological IP. This reflects the sensitivity of these indices to cirrhosis corresponding to the data proposed by Pierce [18] who noted a sensitivity and specificity of $68 \%$ and $70 \%$ from an IR value of 0.77 . However, it should be noted that the increase in the indices is not specific to cirrhosis. Indeed, increased indices are also noted in the chronic diseases of the liver [19], after the meal and with age [20] [21]. It should also be noted that there are significant inter- and intraobserver variations that might affect the measurement of these indices [22].

\subsection{Hepatic Veins}

The decreased size of the hepatic veins and the demodulation (decrease in pulse) of the hepatic vein spectrum in cirrhotic patients can be explained by the decrease of the hepatic parenchyma compliance due to fibrosis and the decrease of hepatic vein diameter. resulting from cirrhosis. [23] [24] [25].

Bolondi \& al [26] and Colli \& al [23] found respectively 50\% and 75\% abnormal spectrum in the cirrhotic patients. 
The decrease of the calibers and the demodulation of the spectrum of the hepatic veins is a sensitive sign of the cirrhosis but nonspecific because the Budd Chiari syndrome, the diffuse hepatic metastases as well as the deep inspiration, obesity, and ascites are the factors that can influence the spectrum of hepatic veins [26] [23] [27] [28] [29] [30].

\subsection{Limitations}

None of our patients received a liver biopsy puncture which is the gold standard for the diagnosis of cirrhosis [2]. The diagnosis of cirrhosis in the hepato-gastroenterology department was based on a combination of clinical, biological and radiological arguments [3].

\section{Conclusions}

We found a statistically significant change in hemodynamic parameters of liver vessels in the cirrhotic patient compared with the non-cirrhotic subject. The size of the portal vein; the hepatic artery average and systolic velocities, the resistance and the pulse index had increased in the cirrhotic. The systolic and diastolic average velocities of the portal vein and the caliber of the hepatic veins, on the other hand, had decreased in cirrhotic patients.

The measurement of hemodynamic parameters of hepatic vessels is a sensitive and specific argument for the diagnosis of cirrhosis. It can and must rightly be part of the diagnosis arsenal of cirrhosis.

\section{References}

[1] Anthony, P.P., Ishak, K.G., Nayak, N.C., Poulsen, H.E., Scheuer, P.J. and Sobin, L.H. (1977) The Morphology of Cirrhosis Definition, Nomenclature, and Classification. Bull WHO, 55, 521-540.

[2] Regev, A., Berho, M., Jeffers, L.J., Milikoswski, C., Molina, E.G., Pyrsopoulos, N.T., et al. (2002) Sampling Error and Intraobserver Variation in Liver Biopsy in Patients with Chronic HCV Infection. The American Journal of Gastroenterology, 97, 2614-2618. https://doi.org/10.1111/j.1572-0241.2002.06038.x

[3] Bouglouga, O., Bagny, A., Djibril, M.A., Lawson-Ananissoh, L.M., Kaaga, L., Redah, D., et al. (2012) Aspects épidémiologiques, diagnostiques et évolutifs de la cirrhose hépatique dans le service d'hépato-gastroentérologie du CHU Campus de Lomé. Journal de la Recherche Scientifique de I Université de Lomé(Togo), 14, 1-7.

[4] Pavlov, C.S., Casazza, G., Semenistaia, M., Nikolova, D., Tsochatzis, E., Liusina, E., et al. (2016) Ultrasonography for Diagnosis of Alcoholic Cirrhosis in People with Alcoholic Liver Disease. Cochrane Database of Systematic Reviews, No. 3. Art. No.: CD011602.

[5] Kok, T.H., van der Jagt, E.J., Haagsma, B.C.M.A., Jansen, P.L.M. and Boeve, W.J. (1999) The Value of Doppler Ultrasound in Cirrhosis and Portal Hypertension. Scandinavian Journal of Gastroenterology, 34, 82-88.

[6] Martinez-Noguera, A., Montserrat, E., Torrubia, S. and Villalba, J. (2002) Doppler in héPatic Cirrhosis and Chronic Hépatitis. Seminars in Ultrasound, CT, and MRI, 23, 19-36. https://doi.org/10.1016/S0887-2171(02)90027-2 
[7] Zironi, G., Gaiani, S., Fenyves, D., Rigamonti, A., Bolondi, L. and Barbara, L. (1992) Value of Measurement of Mean Portal Flow Velocity by Doppler Flowmetry in the Diagnosis of Portal Hypertension. Journal of Hepatology, 16, 298-303. https://doi.org/10.1016/S0168-8278(05)80660-9

[8] Iwao, T., Toyonaga, A., Kazuhiko, O, Tayama, C., Masumoto, H., Sakai, T., et al. (1997) Value of Doppler Ultrasound Parameters of Portal Vein and Hepatic Artery in the Diagnosis of Cirrhosis and Portal Hypertension. The American Journal of Gastroenterology, 92, 1012-1017.

[9] de Vries, P.J., van Hattum, J., Hoekstra, J.B.L. and de Hooge, P. (1991) Duplex Doppler Measurements of Portal Venous Flow in Normal Subjects. Inter- and Intra-Observer Variability. Journal of Hepatology, 13, 358-363. https://doi.org/10.1016/0168-8278(91)90081-L

[10] Bolondi, L., Gaiani, S. and Barbara, L. (1991) Accuracy and Reproducibility of Portal Flow Measurement by Doppler US. Journal of Hepatology, 13, 269-273. https://doi.org/10.1016/0168-8278(91)90067-L

[11] Sabba, C., Weltin, G.G., Cicchetti, D.V., Ferraioli, G., Taylor, K.J.W., Nakamura, T., et al. (1990) Observer Variability in Echo-Doppler Measurements of Portal Flow in Cirrhotic Patients and Normal Volunteers. Gastroenterology, 98, 1603-1616. https://doi.org/10.1016/0016-5085(90)91097-P

[12] Nelson, R.C., Lovett, K.E., Chezmar, J.L., Moyers, J.H., Torres, W.E., Murphy, F.B., et al. (1987) Comparison of Pulsed Doppler Sonography and Angiography in $\mathrm{Pa}$ tients with Portal Hypertension. AJR, 149, 77-81. https://doi.org/10.2214/ajr.149.1.77

[13] Marder, D.M., DeMarino, G.B., Sumkin, J.H. and Sheahan, D.G. (1989) Liver Transplant Rejection: Value of the Resistive Index in Doppler Ultrasound of Hepatic Arteries. Radiology, 173, 127-129. https://doi.org/10.1148/radiology.173.1.2675178

[14] Sacerdoti, D., Merkel, C., Bolognesi, M., Amodio, P., Angeli, P. and Gatta, A. (1995) Hepatic Arterial Resistance in Cirrhosis with and without Portal Vein Thrombosis: Relationships with Portal Hemodynamics. Gastroenterology, 108, 1152-1158. https://doi.org/10.1016/0016-5085(95)90214-7

[15] Joint, L.K., Platt, J.F., Rubin, J.M., Ellis, J.H. and Bude, R.O. (1995) Hepatic Artery Resistance before and after Standard Meal in Subjects with Diseased and Healthy Livers. Radiology, 196, 489-492. https://doi.org/10.1148/radiology.196.2.7617865

[16] Dauzat, M., Lafortune, M., Patriquin, H. and Pomier-Layrargues, G. (1994) Meal Induced Changes in Hepatic and Splanchnic Circulation: A Noninvasive Doppler Study in Normal Humans. European Journal of Applied Physiology, 68, 373-380. https://doi.org/10.1007/BF00843732

[17] Tanaka, K., Mitsui, K., Morimoto, M., Numata, K., Inoue, S., Takamur, Y., et al. (1993) Increased Hepatic Arterial Blood Flow in Acute Viral Hepatitis: Assessment by Color Doppler Sonography. Hepatology, 18, 21-27. https://doi.org/10.1002/hep.1840180105

[18] Pierce, M.E. and Sewell, R. (1990) Identification of Hepatic Cirrhosis by Duplex Doppler Ultrasound Value of the Hepatic Artery Resistive Index. Australasian Radiology, 34, 331-333. https://doi.org/10.1111/j.1440-1673.1990.tb02667.x

[19] Piscaglia, F., Gaiani, S., Zironi, G., Gramantieri, L., Casali, A., Siringo, S., et al. (1997) Intra- and Extrahepatic Arterial Resistances in Chronic Hepatitis and Liver Cirrhosis. Ultrasound in Medicine \& Biology, 23, 675-682. https://doi.org/10.1016/S0301-5629(97)00012-4 
[20] Lafortune, M., Dauzat, M., Pomier-Layrargues, G., Gianfelice, D., Lepanto, L., Breton, G., et al. (1993) Hepatic Artery: Effect of a Meal in Healthy Persons and Transplant Recipients. Radiology, 187, 391-394. https://doi.org/10.1148/radiology.187.2.8475279

[21] Fisher, A.J., Paulson, E.K., Kliever, M.A., Delong, D.M. and Nelson, R.C. (1998) Doppler Sonography of the Portal Vein and Hepatic Artery: Measurement of a Prandial Effect in Healthy Subjects. Radiology, 207, 711-715. https://doi.org/10.1148/radiology.207.3.9609894

[22] Colli, A., Cocciolo, M., Mumoli, N., Cattalini, N., Fraquelli, M. and Conte, D. (1998) Hepatic Artery Resistance in Alcoholic Liver Disease. Hepatology, 28, 1182-1186. https://doi.org/10.1002/hep.510280503

[23] Colli, A., Cocciolo, M., Riva, C., Martinez, E., Prisco, A., Pirola, M., et al. (1994) Abnormalities of Doppler Waveform of the Hepatic Veins in Patients with Chronic Liver Disease: Correlation with Histologic Findings. AJR, 162, 833-837. https://doi.org/10.2214/ajr.162.4.8141001

[24] Walsh, K.M., Leen, E., Macsween, R.N. and Morris, A.J. (1998) Hepatic Blood Flow Changes in Chronic Hepatitis C Measured by Duplex-Doppler Color Sonography. Relationship to Histological Features. Digestive Diseases and Sciences, 43, 2584-2590. https://doi.org/10.1023/A:1026626505517

[25] Arda, K., Ofelli, M., Calikoglu, U., Olcer, T. and Cumhur, T. (1997) Hepatic Vein Doppler Wave-Form Changes in Early Stage (Child-Pugh A) Chronic Parenchymal Liver Disease. Journal of Clinical Ultrasound, 25, 15-19. https://doi.org/10.1002/(SICI)1097-0096(199701)25:1<15::AID-JCU3>3.0.CO;2-N

[26] Bolondi, L., Bassi, S.L., Gaiani, S., Zironi, G., Benzi, G., Santi, V., et al. (1991) Liver Cirrhosis: Changes of Doppler Waveform of Hepatic Veins. Radiology, 178, 513-516. https://doi.org/10.1148/radiology.178.2.1987617

[27] Ohta, M., Hashizume, M., Tomikawa, M., Ueno, K., Tanoue, K. and Sugimachi, K. (1994) Analysis of Hepatic Vein Waveform by Doppler Ultrasonography in $100 \mathrm{~Pa}$ tients with Portal Hypertension. The American Journal of Gastroenterology, 89, 170-175.

[28] Ohta, M., Hashizume, M., Kawanaka, H., Akazawa, K., Tomikawa, M., Higashi, H., et al. (1995) Prognostic Significance of Hepatic Vein Waveform by Doppler Ultrasonography in Cirrhotic Patients with Portal Hypertension. The American Journal of Gastroenterology, 90, 1853-1857.

[29] Hosoki, T., Kuroda, C., Tokunaga, K., Marukawa, T., Masuike, M. and Kozuka, T. (1989) Hepatic Venous Outflow Obstruction: Evaluation with Pulsed Duplex Sonography. Radiology, 170, 733-737. https://doi.org/10.1148/radiology.170.3.2644659

[30] Bolondi, L., Gaiani, S., Bassi, S.L., Zironi, G., Bonino, F., Brunetto, M., et al. (1991) Diagnosis of Budd-Chiari Syndrome by Pulsed Doppler Ultrasound. Gastroenterology, 100, 1324-1331. https://doi.org/10.1016/0016-5085(91)90785-J 